\title{
Aumentando la empatía en entornos virtuales artísticos: La presencia en la imagen esférica desde el avatar invisible
}

\section{Increasing empathy in artistic virtual environments: The presence in spherical image from the invisible avatar}

\author{
TIPO DE TRABAJO: Comunicación. \\ PALABRAS CLAVE \\ realidad virtual; empatía; presencia; imagen inmersiva; arte.
}

KEY WORDS

virtual reality; empathy; presence; immersive imagen; art.

RESUMEN

La imagen actual es tridimensional e interactiva, ahora el espectador se convierte en usuario y se nos sitúa en el centro de una esfera. De este modo un nuevo mundo se hace visible a través de la realidad virtual. En el paradigma de la burbuja, nuestra relación con el entorno ha cambiado, estas imágenes envolventes nos permiten elegir el punto de vista haciendo única la experiencia. Es importante modificar nuestra relación con el entorno tanto en la propia experiencia como posteriormente. Desde la cognición corporal, nuestras relaciones con el entorno virtual nos permiten sentir con mayor intensidad lo que percibimos de el. Este trabajo investiga la relación del usuario en estos entornos virtuales y no virtuales, así como la acción e interacción en entornos inmersivos artísticos. Para ello, utilizo el entorno creado por Marina Abramovic, dividiendo en tres fases diferenciadas la experiencia y la interacción con el avatar de Abramovic desde la ausencia de nuestro avatar en el mundo virtual, es decir, desde la invisibilidad corporal y ausencia de representación visual en el mundo inmersivo. Utilizando esas tres fases y desde la ausencia de nuestro avatar, es posible aumentar la presencia, la conciencia y la empatía por medio de otros mecanismos sensoriales de la experiencia, los elementos de la imagen y otras virtualidades.

\section{ABSTRACT}

Nowadays the image is three dimensional and interactive, now the viewer becomes a user, now is the center of a sphere. A new world can be seen through virtual reality. In the bubble paradigm, our relationship with the environment has changed, these immersive images make us posiible to choose the point of view, making a unique experience. It is important to modify our relationship with the environment. From the embodied cognition, the relationships of our body with the virtual environment allow us to feel with more intensity what we perceive. This paper investigates the relationship of the user in these virtual and non-virtual environments. I use the environment created by Marina Abramovic, dividing the differentiated and the interaction with Abramovic's avatar in the absence of our avatar in the virtual world, that is, in the corporal invisibility and the absence of our avatar, it is possible to increase presence, awareness and empathy through other sensory mechanisms of experience, the elements of the image and other virtualities.

\section{INTRODUCCIÓN}

La imagen ha modificado su forma y con ello la forma en la que nos enfrentamos a ella, ahora la imagen esférica nos envuelve. Como usuarios, entramos en la imagen y la vivimos desde dentro, siendo un elemento más de la misma. Siendo parte de la imagen, el espectador pasa a ser activo y parte fundamental para el desarrollo de la experiencia única. No solo estamos en una burbuja, sino que 
nuestra interacción también se produce con esferas a su vez dentro de mundos esféricos que abren otros y posibilitan la navegación en ellos. Estamos en el paradigma de la imagen burbuja, nuestra interacción en la imagen es por medio de estas burbujas ( $H$. STEYERL). El espectador es parte de ella, de nosotros depende el entorno virtual y el desarrollo que tengamos en él. Nosotros somos la imagen, somos el entorno, y en este espacio virtual, somos el espectador emancipado, (J. RANCIERE, 2010) nos relacionamos e interactuamos con la imagen desde dentro, al mismo nivel que otros avatares en estos entornos soñados. El usuario -y no espectadorse encuentra en la imagen, aunque invisible; usuario e imagen conforman el mundo virtual.

Esta relación tan directa con el entorno se produce con mucha intensidad. Desde la cognición corporal se ha superado el modelo dualista, para entender que conocimiento y emoción no son dos cosas distintas. Por lo tanto, esta experiencia en un entorno virtual, sin límites en la imagen hace que nuestra experiencia se encuentre condicionada por todos los elementos sensoriales del espacio, aunque no se encuentren en nuestro ángulo de visión. Esto nos coloca en una posición privilegiada desde la que vivir el entorno virtual. Nuestras relaciones con el entorno visible en realidad virtual hacen que pongamos mayor nivel de atención y, por tanto, percibamos con mayor intensidad lo que sucede a nuestro alrededor.

Ser parte central de la imagen es fundamental a la hora de relacionarnos con el resto de la imagen 360으, así como para posibilitar la presencia y con el fin de aumentar las sensaciones corporales. Esto es relevante dado que desde la práctica artística tratamos de provocar reacciones y sensaciones, así como al involucrarse de este modo (como usuario activo) aumenta la intensidad de las mismas. En aquellas experiencias en las que contamos con un avatar, este ocupa la parte central de un espacio, pero entran otros avatares que interactúan al mismo nivel con nosotros. En este mundo con forma esférica, somos el centro de la imagen, ocupada con nuestro avatar, y cada uno centro de otra imagen que viene determinada por su posición en el entorno virtual. Generando así, desde lo esférico, una inmersión visual que nos permite explorar las imágenes de otro modo.

En este trabajo se abordará la relación del usuario en los entornos virtuales inmersivos y como se produce la interacción en los mismos. Me serviré de la obra de Marina Abramovic, "Rising" (2018) que trata de generar empatía hacia los demás y con los cambios que se están produciendo en nuestro planeta. Analizaré las tres fases que utiliza para generar un traspaso de energía entre ella y nosotros en el mundo virtual y aumentar nuestra empatía sin la necesidad de que tengamos un avatar visible. Con el objetivo de demostrar la (innecesidad) de un avatar visible en la experiencia, sino que por medio de otras virtualidades en la imagen se puede lograr una conexión empática con el avatar de Marina Abramovic. Utilizando esas tres fases y desde la ausencia de nuestro avatar, es posible aumentar la presencia, la conciencia y la empatía por medio de otros mecanismos sensoriales de la experiencia, los elementos de la imagen y otras virtualidades.

En este trabajo utilizaré la obra de Marina Abramovic para abordar los aspectos clave de la experiencia de obras inmersivas artísticas, que logran generar empatía. Son relevantes las fases utilizadas en este tipo de experiencia, con el fin de mediar y controlar la experiencia para establecer la suspensión de la incredulidad y aumentar nuestra presencia.

A partir de la imagen estereoscópica, aparece visible otro mundo por medio de un casco de realidad virtual, que además posibilita dirigir nuestra mirada a cualquier punto, sin limitaciones. La imagen nos envuelve 360, estamos rodeados de imagen como si nosotros fuéramos el centro de una esfera y nuestro punto de atención marcará nuestra experiencia, nunca será la misma imagen. En este punto, nuestra atención se dirigirá hacia un punto, pero determinados elementos harán que modifiquemos nuestra atención a otro punto, manteniendo en nuestro ángulo de visión en una pequeña parte de nuestra esfera. Desde el arte, ya se asume la realidad virtual como una nueva herramienta que posibilita generar nuevos entornos.

\section{DESARROLLO}

Marina Abramovic genera la pieza "Rising" (2018) en la que pretende aumentar nuestra conciencia por el cambio climático. Se trata de una pieza inmersiva que se nos plantea en los mismos tres niveles que Guattari plantea en su libro Las tres ecologías (1996). Todos los actos nos conducen a modificar nuestras acciones con el entorno y por tanto, con nuestra relación con los demás. Para esta pieza en el mundo virtual, ella se sumerge en una piscina, y sus movimientos y reacciones grabadas se utilizan posteriormente para generar su avatar y las reacciones del mismo. En la experiencia, nosotros nos adentramos en un entorno, rodeados de imagen, sin un avatar que haga evidente nuestra presencia. Somos la parte central de la esfera que determina la orientación, pero carecemos de un cuerpo u avatar en el caso de esta experiencia. En este caso, consigue aumentar la presencia por otros métodos que se explican más adelante. A mitad de la experiencia, nos enfrentamos al avatar de la artista, desde la estructura planteada, no existe un cuerpo en el mundo virtual, somos invisibles en la imagen. Esto se produce debido a que nuestra atención está dirigida a un punto determinado, apenas utiliza un tercio de los 360 para desplazar la atención. 


\section{Mediando en la experiencia}

Una parte fundamental en la experiencia con el entorno virtual, es previa a la inmersión. Algunas propuestas como "Chalkroom" (Anderson, L., 2017) ${ }^{1}$, modifican el espacio antes de la colocación del casco inmersivo para controlar la experiencia. Con esta práctica se consigue mediar la experiencia con mayor facilidad. Las propuestas no situadas en espacios expositivos, o sobre las que no existe ningún control, deben cuidar mucho los primeros minutos en la experiencia para lograr la presencia. Es el caso de la obra "Rising" de Marina Abramovic, donde a pesar de ser una experiencia 360으, nuestra atención se limita siempre a un pequeño ángulo. A pesar de contar con mucho más espacio, solo es visible una pequeña parte del entorno. En este corto espacio virtual, es donde nos introduce en su experiencia utilizando una introducción mucho más mediada, añadiendo mayor control. Nuestra atención se dirige únicamente a un punto, el resto aparece a oscuras, sin información visual ni sonora.

Este pequeño espacio nos sitúa en las problemáticas que abordará posteriormente y también nos muestra como es su entorno. Uno de los elementos fundamentales que utiliza para conseguir la inmersión es el holograma en ese espacio. Dos hologramas dan cuenta de que lo que no pertenece a esta realidad son esas proyecciones, pero sí todo lo demás, aumentando nuestra presencia en ese instante. Los hologramas funcionan a la perfección en esta parte de introducción tanto a la problemática que aborda como a las experiencias sensoriales que abordará con posterioridad. Colocados uno a cada lado de la entrada, nos reciben en la experiencia. El holograma nos recuerda que para experimentar desde lo corporal todas las sensaciones que la artista llevará a cabo en la siguiente fase, primero debe llevarnos mentalmente a ese espacio concreto y lo logra utilizando otras imágenes dentro de una imagen mayor.

En este caso, al ser parte de la imagen misma, conocemos este entorno a partir de nuestra inmersión en la experiencia. Ya no es espectador, sino, como dice Marina Abramovic en la experiencia (2018), "players", es decir, jugadores. Estos jugadores son parte del entorno, están en la parte central y aprenden desde la experiencia, esto es, conocimiento enactivo (Varela, F.J., 1992). A pesar de nuestras limitaciones con relación al movimiento y visibilidad en la experiencia, así como nuestra carencia de avatar, se ven relegadas a un segundo plano de la atención. El espectador y la obra interactúan de otro modo, en estas experiencias inmersivas no hay espectador ni observador (Grau, O., 2003) y esto se ve claramente en la manera de afrontar la obra de Marina Abramovic, involucrándolo de forma activa y convirtiéndole en jugador.

La propia imitación de la textura del holograma dentro de la experiencia con aspecto realista, separa y aleja lo no físico, creando a su vez otro continuo de la virtualidad (MILGRAM, P. y KISHINO, F., 1994) dentro de la realidad virtual propiamente dicha, que pretende imitar al mundo físico. Con la introducción de elementos que evidencian lo no físico como es el holograma, nos hace pensar en la fisicidad de todo lo demás perteneciente a la experiencia.

\section{Performatividad visible}

En una segunda fase, se encienden las luces del entorno y se nos presenta un mayor espacio iluminado, donde realmente comienza la experiencia para los jugadores que según la artista tendrán la oportunidad de salvar vidas. Tras introducirnos en la experiencia en sí, explica la intencionalidad en relación con la problemática medioambiental que ya nos ha introducido en la primera fase, y que ha servido para mediar y orientar la experiencia que comienza. En esta fase, comienza a introducir la experiencia, utiliza varias fases con el fin de controlar, en la medida de lo posible, las sensaciones. Aumenta la presencia e inmersión del usuario, y logra generar mayor empatía en el usuario. Tras la introducción pertinente sobre los cambios que se están produciendo, se nos descubre otro mundo donde comienza la acción de Marina Abramovic, aparece su avatar, dentro de una urna que comenzara a subir su nivel de agua, pero al mismo tiempo, su avatar situado frente a nosotros, habla y se comunica con gestos. Mediante el uso de un avatar enfrentado a nosotros trata de aumentar la empatía y conciencia por el cambio climático en el mundo no virtual.

A pesar de carecer de un avatar, en mi experiencia no se hizo necesario, dado que nuestra mirada se induce a enfrentarnos con el avatar de la artista. En ese momento, la mirada se fija en ella y se aparta totalmente de nosotros. En este caso nos centramos en ella y también prestamos atención a lo que nos está narrando. Su avatar funciona frente a nosotros con un cristal que nos separa, de este modo empatizamos con ella y tratamos de ayudarla. Con esto trata de que hagamos algo para ayudar a la artista y al planeta.

En esta parte aumenta el ángulo de visión en el entorno, así como la interacción con el avatar de Marina Abramovic. En unas tres frases, Marina nos narra como va a generar la empatía en los próximos minutos, esto sucederá si nosotros tratamos de ayudarla de algún modo o de salvarla ya que se producirá un cambio de energía y también un cambio en la conciencia de los usuarios por el cambio climático.

\footnotetext{
${ }^{1}$ La experiencia “Chalkroom" (2017) de Laurie Anderson y Hsin-Chien Huang, se cuida la presentación de la obra, empezando por el espacio previo que cuenta con los mismos dibujos que veremos al adentrarnos en su mundo virtual. Pero también a posteriori en la propia experiencia, introduciendo fases diferenciadas.
} 
Si bien muchos autores prescinden de la primera fase y entran directamente, en esta dado el nulo control que se ejerce previamente a la experiencia, puede no conseguir la inmersión deseada. En estos casos dependiendo de la experiencia, deberá comenzar gradualmente e incluir otros elementos que aumenten nuestra sensación de presencia y que actúen sobre una "Suspensión de la incredulidad" más relacionada con nosotros y el entorno que con la hiper-realidad de lo que vemos.

\section{Empatía y energía; el avatar reflejado}

La segunda fase en la obra de Marina Abramovic termina con un interrogante, se pregunta qué sucederá, si bien, aunque estemos en realidad virtual, trataremos de ayudar y se producirá ese cambio de energía en el usuario. Pero esto que la artista propone no es solo en la experiencia, también se plantea al finalizar. En este momento comienza la tercera parte con su performance dentro de este recipiente rectangular, y donde nuestra empatía con ella, marcará el futuro de la experiencia y la performance. El discurso junto con su acción performativa en el interior del cubículo va aumentando su intensidad al igual que aumenta el nivel de agua en el tanque y en el planeta. Pero como ya he mencionado anteriormente, su finalidad no es únicamente generar conciencia por el cambio climático en ese mismo momento, trata de generar mayor empatía con nuestro planeta a través de la empatía con ella y la energía transferida entre nosotros y a largo plazo de su avatar.

Su avatar en este caso, se enfrenta a nosotros a modo de espejo para generar la empatía desde la segunda fase. Su avatar conecta con nosotros por medio de estas características que he mencionado, aumentando la empatía, pero realmente genera conciencia por el cambio climático cuando se produce ese intercambio de energía en el mundo virtual, dado que esa energía se mantiene después de la experiencia. La energía es relevante en esta experiencia, si bien como la artista plantea abordar en la experiencia: si se transfiere energía cuando alguien rescata a otra persona o la ayuda de algún modo y como se sucedería en un entorno de realidad virtual (Abramovic, M., 2018). En esta experiencia su avatar está ahí para que le ayudemos y se produzca ese intercambio de energía que afectará tanto en el videojuego como con posterioridad, cumpliendo su propuesta de otorgar energía al usuario y que se produzcan los cambios, como Artaud propuso otorgar las energías a la comunidad en el teatro (1969). Aunque también se reflejan dudas por parte de la artista de si trataremos de ayudarla o salvarla de algún modo. Pero realmente lo que Marina pretende más allá de salvar a su avatar de ahogarse en un tanque virtual, es aumentar la conciencia de los usuarios poniendo en sus manos tomar parte de la acción y salvar al planeta de las inundaciones catastróficas que se prevé que tengan lugar en los paisajes urbanos (Abramovic, M., 2018). Se pretende que la experiencia vivida afecte con posterioridad, en el mundo físico. La realidad virtual consigue que nuestra atención aumente considerablemente y esto conlleva que aumente la intensidad a la hora de generar sensaciones, lo vivimos con más intensidad, y lo retenemos más tiempo en nuestra memoria.

Para que nosotros podamos llevar a cabo estas pequeñas acciones por el planeta, lo que Abramovic nos propone es que seamos activos y contribuyamos con pequeñas acciones que, a una escala planetaria, van a suponer un gran cambio. Junto con esta performance, la artista ha lanzado una aplicación ${ }^{2}$ para que a nivel individual cada uno se comprometa a realizar pequeños cambios en su día a día. Funciona como una extensión de la misma, que es capaz de facilitar y hacernos más conscientes si cabe, de la problemática y lo importante que es nuestra acción para reducir el impacto medioambiental.

La experiencia en el mundo físico recrea lo que podría haber sido una performance de Marina Abramovic físicamente, los elementos que aparecen hacen referencia a otros objetos del mundo físico. Si bien otras experiencias abordan la construcción de este entorno con una base basada en los elementos físicos, también introducen otros elementos que se superponen. Estas imágenes que se sitúan sobre otras imágenes, generando unas nuevas que reaccionan a nuevos movimientos. Marina se separa de este tipo de experiencias y se acerca a una "imitación" de las propiedades físicas, así como de los objetos, posiblemente, con el fin de efectuar esa suspensión de la incredulidad para favorecer la inmersión.

El avance en la experiencia se produce de forma pasiva, no requiere de ninguna acción en nosotros para avanzar al siguiente nivel. Pero también es un desplazamiento controlado que nos dirige y teletransporta a otro nivel. Se trata de una experiencia que partiendo de un breve ángulo de los 360 disponibles, logra llegar a la inmersión completa, en los 360ำen una balsa en medio del océano.

\footnotetext{
2 La aplicación que lleva el mismo nombre la pieza inmersiva de Realidad Virtual, Rising fue lanzada coincidiendo con The Nobel Week Dialogue.
} 


\section{CONCLUSIONES}

En la era del Antropoceno donde la acción del ser humano está cambiando aceleradamente, se presenta al ser humano como centro de los cambios que se están produciendo en el planeta. Nosotros como centro de un mundo virtual cambiante y en perpetuo cambio, decidimos el punto al que dirigir la atención. Este tipo de imágenes que nos envuelven, enseguida activan nuestros mecanismos sensoriales y hacen que percibamos con mayor intensidad, permitiendo, desde lo artístico, enviar un mensaje y recibirnos como usuarios a partir de la experiencia. Lo importante de estas experiencias es que afecten tanto a la experiencia virtual como posteriormente a nuestra relación con el entorno y los demás. Como sucede en la propuesta de Marina Abramovic "Rising" (2018) en la que tras ponernos en situación sobre las consecuencias que estamos sufriendo en nuestro planeta, nos sumerge en su propuesta performativa.

La primera fase sirve para controlar la experiencia, así como lo que va a suceder con posterioridad. Es importante que los primeros segundos nos introduzcan de un modo apropiado, dado que no tenemos control sobre lo anterior a colocarnos los cascos de realidad virtual. La antesala que muestra Marina Abramovic es uno de los puntos clave para aumentar la presencia sin la necesidad de la presencia visible de un avatar propio. Las posibilidades para adentrarnos en un mundo virtual son infinitas, la importancia recae en conseguir la suspensión de la incredulidad al comienzo de la experiencia, para poder aumentar las posibilidades de crear esa conexión con el avatar.

Lo que está claro es que la tecnología de Realidad Virtual abre un camino directo con los sentidos, las emociones e incluso el cuerpo. En esta experiencia utilizando nuestra capacidad de empatía y de colocarnos en el lugar del avatar de la artista, nos ha conducido a tratar de salvarla y por tanto de contribuir con el planeta. Ese traspaso de energía es necesario que se produzca para tener efectos con posterioridad en nuestro entorno.

No es imprescindible el uso del avatar en primera persona para generar empatía, es posible mediante una introducción mediada que aumente la presencia en el entorno citado. El uso de un avatar, ayuda a generar empatía con mayor facilidad, pero no por ello impide que en otros casos no se genere esa conexión, como sucede en el caso de Abramovic. En esta experiencia la utilización de elementos como el holograma resultan fundamentales. Para aumentar la presencia, la utilización en un primer momento de elementos o imágenes pertenecientes al mundo de las imágenes "virtuales" contribuyen a situarnos en un mundo que es totalmente imagen. Esta utilización de elementos de imágenes dentro de otra imagen, ayudan aumentando la presencia.

Es por todas las características anteriores, por lo que la obra de Marina Abramovic tiene mayores implicaciones a nivel mental, social y medioambiental. La obra es capaz de modificar nuestra empatía con los demás así como con el planeta, por medio de pequeños cambios que podemos llevar a cabo de forma individual. Modificando nuestra forma de interactuar en el videojuego, puede generar un cambio en nosotros para que posteriormente tenga repercusiones en el mundo físico y por tanto, en el medio que nos rodea.

\section{AGRADECIMIENTOS}

Esta investigación ha sido financiada por el Ministerio de Ciencia, Innovación y Universidades dentro del proyecto "Arte y cognición corporal en los procesos de creación: sensibilización ecológica del yo en el entorno" (HAR2017-85485-P). La autora está apoyada por una ayuda FPU (Formación de Profesorado Universitario) del Ministerio de Ciencia, Innovación y Universidades. (ref: FPU2017/03492).

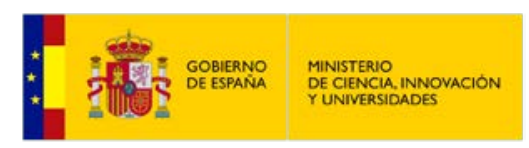




\section{FUENTES REFERENCIALES}

Abramovic, M. (2018). Rising.

Anderson, L., Huang, H.C. (2017). Chalkroom.

Artaud, A. (1969). El teatro y su doble. Instituto del libro.

Grau, O. (2003). Virtual Art: from Illusion to immersion. Cambridge: MIT Press.

Guattari, F. (1996). Las tres ecologías. Valencia: Pre-Textos.

Milgram, P. y Kishino, F. (1994). Augmented Reality: A class of displays on the reality-virtuality continuum in Procedings of Telemanipulator and Telepresence Technologies. pp. 2351-34.

Ranciere, J. (2010). El espectador emancipado. Buenos Aires: Ediciones Manantial.

Steyerl, H. (2014). Los condenados de la pantalla. Buenos Aires: Caja Negra.

Varela, F.J. (1992). De cuerpo presente: las ciencias cognitivas y la experiencia humana. Barcelona: Gedisa. 